\title{
Clear Cell Carcinoma Ovarii with Metastasis to the Peritoneum: A Case Report and Literature Review
}

\author{
Intan, $\mathrm{SA}^{1}$, Yenita ${ }^{2}$ \\ \{shintaayuintan@med.unand.ac.id ${ }^{1}$, yenita@med.unand.ac.id $\left.{ }^{2}\right\}$
}

Anatomical Pathology Department of Anatomical Pathology Medical Faculty, Universitas Andalas.

J1. Perintis Kemerdekaan No. 94, Padang 25127, West Sumatra, Indonesia

\begin{abstract}
Clear cell carcinoma (CCC) ovarii was a tumor of the ovary that was pertaining to endometriosis the ovary and the pelvis.At the time diagnosed many of CCC have metastasized on the surface of the pelvis, an abdomen or the bladder.Clear cell carcinoma also had tendency implantation in cavum peritoneum of the diaphragm, paracolic channel and omentum. Cytology could serve as an instrument that is useful in the diagnosis of cystic and dense lesions of the ovary. Peritoneal washing was a part of the procedure to define stadium ovary neoplasm, and it was one of important implementation of cytology. The aim of this study to describe the clinical approach for determination stage and patient prognosis with clear cell carcinoma ovarii. This is a case report with literature review. The patient had an illness history of endometriosis and adenomiosis that never resected. Clinical examination showed a mass at quadrant of the bottom right of the abdomen with the dimension $15 \times 11 \times 8 \mathrm{~cm}$. Imaging examination of ultrasound graphy (USG) showed cystic mass with the dimension $13 \times 10 \times 10 \mathrm{~cm}$. The surgeon reported there were mioma looked the uterus as much as, also a cyst in the ovary right. The ovary left there was adhesion of the intestine and omentum. Histopathology was clear cell carcinoma ovarii. Peritoneal washings clear cell carcinoma ovarii. Clear cell carcinoma when diagnosed is found to have been metastasized. Confirmation cytology with histopathology was obligatory in interpreted peritoneal washing because it is an important to factor in determination stage and prognostic patients.
\end{abstract}

Keywords: Clear Cell Carcinoma Ovarii, Histopathology, Peritoneal Washing.

\section{Introduction}

Clear cell carcinoma (CCC) ovarii is a tumor of the ovary that is pertaining to endometriosis the ovary and the pelvis. At the time of diagnosed many of CCC have metastasized on the surface of the pelvis, an organ the abdomen or the bladder. Clear cell carcinoma also has tendency implantation in cavum peritoneum of the diaphragm, paracolic channel and omentum.[1]

Lesions of cyst or a mass frequent found in the ovaries. Observation usually found on cyst sized about 5-10 cm, while laparotomy suggested for supersized cyst or if there are components solid. In addition, laparotomy also suggested when fluid is in the pelvis enter the abdominal cavity, this peritoneal liquid needed for cytology analysis.[2],[3]

Cytology can serve as a useful instrument for diagnosis cystic and dense lesions of the ovary. Peritoneal washing is a part of the procedure to define stadium on an ovary neoplasm and it is one of important implementation of cytology. One of a cytology sample that used for 
diagnostic an ovary neoplasms is peritoneal washing. Classifications stadium from the International Federation of Gynecology and Obstetrics (FIGO) for ovary neoplasms have been combining the results of peritoneal washing cytology as a part for determining an optimal stadium.[2],[3]

Confirmation cytology with histopathology is obligatory in interpreted peritoneal washing because it would be classified as into stadium IC. Hence, determination of the stadium is one of the important factors in stadium determination and patients prognosis.[2],[4]

\section{Result}

A 45 years old female complained a lump on the bottom right abdomen got measurably bigger since 2 years ago without decreased body weight, nausea and vomited. Clinical examination showed a mass at quadrant of the bottom right abdomen with the dimension $15 \times 11 \times 8 \mathrm{~cm}$, pain tenderness, and dullness percussion. The patient has a past illness history of endometriosis and adenomyosis that never resected. Until now the patient does not have a child. Imaging examination of ultrasonography (USG) showed cystic mass with the dimension $13 \times 10 x$ $10 \mathrm{~cm}$. The surgeon reported there is mioma looked the uterus as much as, looked a cyst in the ovary right. The ovary left difficult for graded (adhesion of the intestine and omentum). Macroscopy examination showed a piece of a cyst tissue, white brownish, the dimension $11 \times 8 \times 5$ $\mathrm{cm}$, cross section looked a multilocular cyst contains a pellucid fluid, the diameter of $6-9 \mathrm{~cm}$, there were looked: solid parts, white brownish, hemorrhagic, thick and thin wall (figure.1).

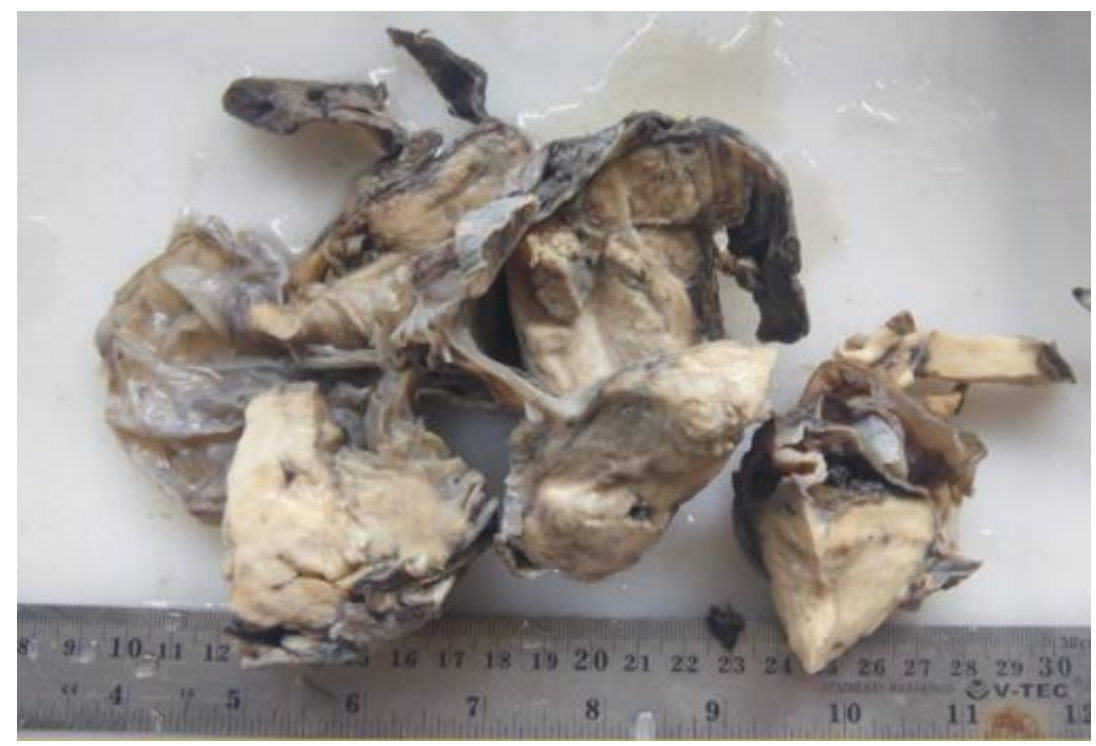

Fig. 1. Macroscopy examination

Histopathology, there were tubulocystic, papillary and solid patterns. The tumor cells vary from polygonal to cuboidal; the cytoplasm ranges from clear to less commonly eosinophilic. The most tumor also contains cells with apical hyperchromatic nuclei (Hobnail cells). Other 
parts contain endothelial leukocyte cells (figure.2) - the definitive diagnosis is clear cell carcinoma ovarii.

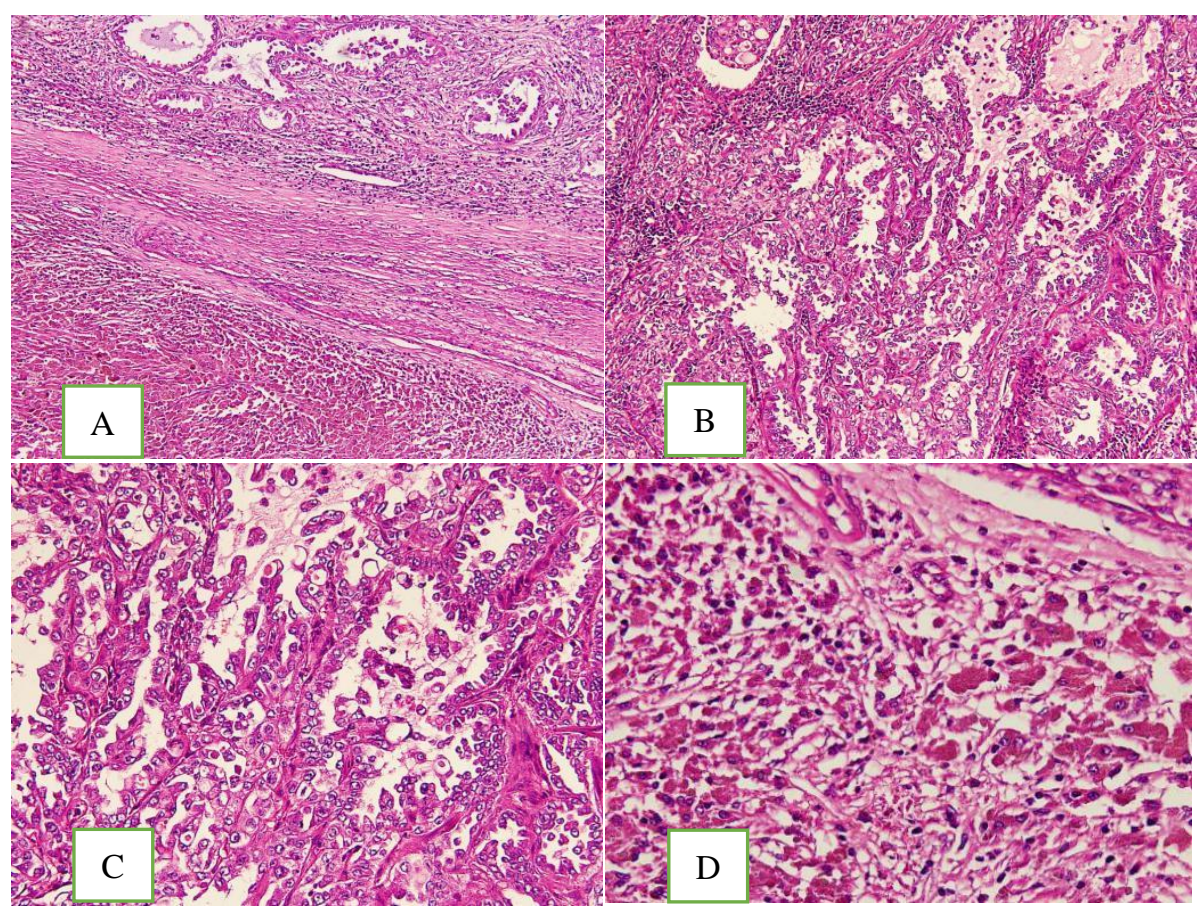

Fig. 2. Histopathology of the tumor is clear cell carcinoma (Hematoxylin-Eosin, original magnification a. tubulocystic patterns $10 \times 10$, b. papillary and solid patterns 20x10, c. hobnail cells20x10, d. endothelial leukocyte40x10).

Peritoneal washing examination showed a group of tumor cells polygonal to columnar; the cytoplasm ranges from clear to less commonly eosinophilic. The most tumor also contains cells with hyperchromatic and eccentric nuclei - that suspicious of malignancy (figure.3).

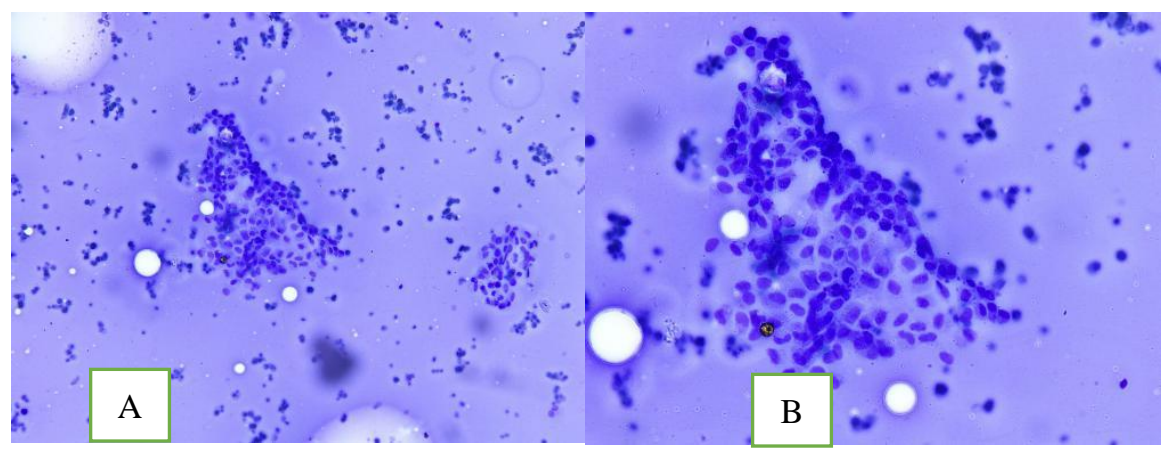



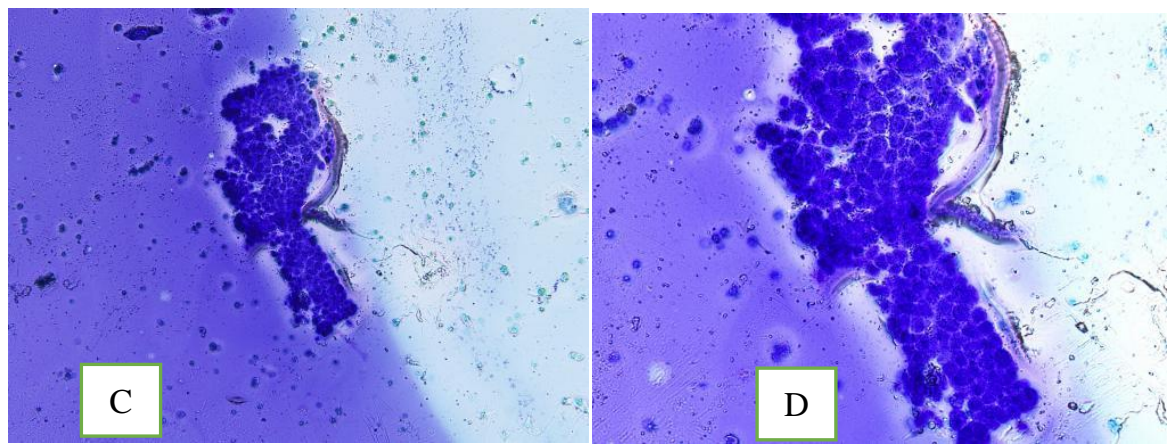

Fig. 3. Peritoneal washing examination (Giemsa, original magnification a,b. columnar cells 20x10, 40x10, c,d. polygonal cells20x10,40x10).

\section{Discussion}

In this case report, a patient with a lump on the bottom right abdominal. Symptoms inflicted usually associated with a mass in the pelvis or abdomen which is about 50-70\% cases ${ }^{[4]}$ Based on social and economic history patients do not have a child. According to Nucci and Oliva in 200 , about 2/3 of women who suffer CCC is nullipara. Based on the past illness history known that patients diagnosed endometriosis and adenomyosis. Clear cell carcinoma ovarii is closely related to endometriosis. More than 50 percent of cases pertaining to atypical endometriosis.[5]

Macroscopy examination showed a piece of a cyst tissue, white brownish, the dimension $11 \times 8 \times 5 \mathrm{~cm}$, cross section looked a cyst have many cavities contains a pellucid fluid, the diameter of 6-9 cm, there are parts of solid, white brownish, hemorrhagic, the wall is thick and thin. Clement and Young state that $\mathrm{CCC}$ is varying from a cyst unilocular until multilocular to the mass of cystic until solid and some accompanied by cyst endometriosis. The contents of a cyst could be a pellucid fluid, mucin or brownish color.

Histopathology, this tumor displays tubulocystic, papillary and solid patterns with cells vary from polygonal to cuboidal also contain cells with apical hyperchromatic nuclei (Hobnail cells) and the cytoplasm ranges from clear to less commonly eosinophilic. It is in accordance with literature which a clear and cytoplasm and a hobnail cell were a most common cell that found in CCC.[1],[6] The result of the accumulation of glycogen not from mucin at clear cytoplasm. While it was emphasized that clear cytoplasm should not be used as the main criteria diagnostic because an ovary tumor has many cell types, there is a cell with eosinophilic cytoplasm but not all consist of that. A CCC supposed to be diagnosed histopathology based on cuboidal identification shape of the cell, distinctive nuclei and the most important of distinctive architecture.[7]

Peritoneal washing examination showed a group of tumor cells polygonal to columnar, the cytoplasm ranges from clear to less commonly eosinophilic. Most tumor also contains cells with hyperchromatic and eccentric nuclei. That suspicious of malignancy. After the result confirmed with histopathology, preparation gives the impression of a metastasis clear cell carcinoma ovarii on liquids peritoneum. Based on stadium FIGO is a stage I C. World Health Organization (WHO)stage IC having a bad prognostic.[1] 
Somewhat less than $1 / 3$ patients diagnosed CCC at the time were diagnosed in the peritoneum, or the lymph has metastasized. Clear cell carcinoma has tendency implantation in cavum peritoneal diaphragm, paracolic channel and omentum [7],[8]. These patients, CCC only occurred in the ovary dekstra.A tumor the ovary with the location of unilateral around $98 \%$ in stage I.[9],[10]

\section{Conclusion}

Clear cell carcinoma is a case when diagnosed is found to have been metastasized. Confirmation cytology with histopathology is obligatory done in interpreting peritoneal washing where later on is an important factor in the determination of stage and prognostic patients.

\section{References}

[1] Kauman RJ et al.: Tumours of The Ovarium. In Kauman, Will, Smith. WHO Classification of Tumour Female Reproductive Carcinoma $4{ }^{\text {th }}$ ed. Lyon.33-6 (2014)

[2] Chieng et al. Epithelial Neoplasms of Ovarii. Chien, John, Smith, ed. Cytology and Surgical Pathology of Gynecologic Neoplasms. Humana Press. 145-57 (2011)

[3] Wilikinson.: Overview of Epithelial Carcinoma Ovarium. Pathology of The Ovarian Fallopian Tube and Peritoneum. UK: Springer.189-92 (2014)

[4] Kurman et al.: Surface Epithelial Tumours of The Ovary. Blaustein's Pathology of Female Genital $6^{\text {th }}$ ed. London. Springer. 2011: 693-772 (2011)

[5] Fletcher CD.: Tumours of the Female Genital Tract. Diagnostic Histopathology of Tumours 4 th ed. Vol 1. Elsevier. 682-4 (2016)

[6] Clement and Young. Surface Epithelial- Stromal Tumours. Atlas of Gynecologic Surgical Pathology $3^{\text {rd }}$ ed. Elevier.392- 95 (2014)

[7] Soslow RA and Thomos. Pathology of Clear Cell Carcinoma. Diagnostic Pathology of Ovarium. Springer. 91-7 (2011)

[8] Prat J. Pathology of Cancers of The Female Genital. International Journal of Gynecologic and Obstetric. 810-19 (2012)

[9] Crum et al. Pathology Based Managemen and Outcome of Epithelial Tumour Ovary. In: Crum, Roger, Nucci, ed. Diagnostic Gynecologic and Obstetric Pathology $2^{\text {nd }}$ ed. Philadelphia: Elsevier. 901-10 (2011)

[10] Barakat et al. Epithelial Carcinoma Ovarium. In: Barakat, George and Thomas, ed. Principle and Practise of Gynecologic Oncology $5^{\text {th }}$ ed. London: Lippincott Williams Walkins. 809-23 (2009) 